\title{
Perspektif Kultural Pengelolaan Lingkungan pada Masyarakat Adat Cikondang Kabupaten Bandung Jawa Barat
}

\author{
BILLYARDI RAMDHAN ${ }^{1,2}$, TATIK CHIKMAWATI ${ }^{*}$, EKO BAROTO WALUYO ${ }^{3}$

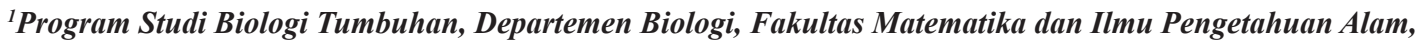 \\ Institut Pertanian Bogor, Kampus Dramaga, Bogor 16680 \\ ${ }^{2}$ Program Studi Pendidikan Biologi, FKIP Universitas Muhammadiyah Sukabumi, Sukabumi 43113 \\ ${ }^{3}$ Bidang Botani Puslit Biologi LIPI Cibinong
}

Diterima 28 November 2014/Disetujui 5 Januari 2015

\begin{abstract}
Peoples of Traditional Cikondang Village, located in the village of Lamajang, Pangalengan, Bandung City West Java have a very close relation to the environment along with its natural resources. This relation is expressed in the form of procedures and rules on the management and utilization of landscape units as well as the diversity of plants as a form of adaptation to the natural environment. This research was conducted through ethnographic method for photographing people's lives and ethnobotany to know the biological resources that are important to Cikondang's people's daily lives. Descriptive and analytical methods are used through interviews with 87 respondents and 4 key informants. Results of research on landscape units that were identified by the community, indicates that in terms of the character, function, and its management there are 9 units of landscape that is both natural landscape and which has been modified by Cikondang community activities. Each unit of the landscape is characterized by vegetation cover according to the type of value in order for daily life. Meanwhile, cultural factors, economic, and political could be a trigger to the landscape transformation of one type of landscape into other landscapes.
\end{abstract}

Key words: Landscape, Ethnobotany, Indigenous Village Cikodang

\section{PENDAHULUAN}

Isu global tentang budaya dan keanekaragaman hayati selalu muncul dan menjadi pembicaraan dalam berbagai kovensi, seperti Ramsar (1975), CITES (1975), CBD (1992), dan konvensi tentang perubahan iklim yang kemudian diperbaharui dalam Protokol Kyoto (1997) serta Protokol Cartagena (2004). Sejauh ini perhatian para ahli mengenai ancaman terhadap kehidupan flora, fauna dan mikroba yang diakibatkan kegiatan manusia telah banyak dilakukan. Kartawinata \& Whiten (1991) menjelaskan Hilangnya Keanakeragaman Biologi memberikan gambaran tentang pentingnya keanekaragaman hayati beserta ekosistem dalam setiap aspek kehidupan.

Banyak cara untuk mengungkapkan bahwa Indonesia adalah negara yang memiliki karakteristik unik. Selain kaya sumberdaya hayati, Indonesia juga memiliki kelompok-kelompok etnis yang jumlahnya ratusan. Setiap kelompok etnis memiliki kehidupan social, ekonomi, budaya yang berbeda dan sangat bergantung pada ekosistem tempat mereka bermukim (Waluyo 2008). Kekhasan masing-masing kelompok etnis ini juga berpeluang melahirkan berbagai

*Penulis korespondensi. Phone: +62-81314215979

E-mail: tchikmawati@yahoo.com pengetahuan tentang alam dan lingkungan (Walujo, et al 1991). Manusia secara naluriah banyak mengambil manfaat terhadap alam lingkungan, terutama untuk bahan bangunan, air, sumber pangan, sumber obatobatan, dan sumber bahan kerajinan (Sastrapraja et al. 1979). Oleh karena itu berbagai unsur sosial, budaya, ekonomi, teknologi, dan politik yang tumbuh dan berkembang di setiap kelompok etnik mempengaruhi cara pandang dan pengelolaan terhadap alam lingkungan. Pengetahuan tersebut membangun system tata nilai budaya sebagai satuan ide dan gagasan dalam kebudayaan yang mempengaruhi aktivitas dalam system social (tata cara, perilaku, dan cara hidup kelompok), serta mempengaruhi kreativitas dalam sistem teknologi (Suparlan 1980).

Pengetahuan masyarakat lokal terhadap lingkungan alam sekitarnya merupakan produk sampingan dari salah satu upaya dalam mempertahankan kelangsungan hidup serta mengembangkan keturunannya (Waluyo et al. 1991). Proses pemenuhan kebutuhan melalui seleksi dan upaya mengenal tumbuhan yang bermanfaat menjadi pengetahuan yang terus dijaga dan diteruskan secara turun temurun. Setiap waktu, pengetahuan yang dibentuk leluhurnya akan terus dicek kebenarannya dan akan terus menerus disempurnakan oleh generasi-generasi berikutnya sebagai bagian dari budaya. Peranan sumber daya 
alam yang sangat besar bagi masyarakat lokal memaksa mereka untuk membentuk suatu sistem tata kelola akan sumber daya alam yang ada. Sistem tata kelola yang dibuat oleh masyarakat adat menjadi suatu kebiasaan adat, hukum adat, atau wasiat adat. Hal ini yang menjadi bagian penting dari pengetahuan masyarakat.

Kampung Adat Cikondang terletak di Selatan Kota Bandung merupakan satu dari sembilan kampung adat yang ada di Jawa Barat. Pengetahuan dan interaksi masyarakat sunda di Kampung Adat Cikondang dengan alam sekitar terutama hutan Gunung Tilu diperlihatkan dengan adanya tata pengaturan lansekap ekosistem yang bertingkat yang mencerminkan kearifan terhadap lingkungan, serta aturan-aturan yang mengikat masyarakatnya yang didasarkan atas dasar "Pamali" (hukum dosa). Dengan tatanan seperti ini, masyarakat tidak banyak mengeksploitasi hutan, akan tetapi dituntut untuk terbiasa menanam sendiri di lingkungan sekitar tempat tinggal, bahkan harus terus menjaga kelestarian hutannya sebagai bagian dari wasiat leluhur "gunung tilu tetep lestari kaian, lahan lamping awian, lahan rata datar imahan, lahan legok balongan, lahan lebak sengkedan sawahan, jeung piara jalan cai solokan" (Gunung Tilu tetap lestari dengan pohon kayu, lahan miring tanam bambu, lahan rata dibuat rumah, lahan cekungan dibuat kolam, lahan lembah dibuat sengkedan untuk persawahan, dan pelihara saluran air) (Darsyah 2012 April 12, komunikasi pribadi).

Kearifan masyarakat Cikondang dalam mengelola lingkungan beserta sumber daya tumbuhannya berimbas pada pola pengaturan lanskap yang diikat oleh aturan adat yang mengikat masyarakatnya untuk patuh pada wasiat leluhur agar tetap terjaga. Upaya mempertahankan wilayah yang menjadi tumpuan kehidupan dan aktifitas masyarakat sehari-hari dilakukan dengan cara penataan dan pengelolaan lanskap yang diatur oleh adat secara turun temurun. Pola aturan penggunaan, pengelolaan, dan penataan masih bersifat tradisional dan ditetapkan sebagai bagian dari aturan adat yang telah diuji secara empirik.

Pentingya keberadaan lanskap yang menjadi tumpuan dan sumber daya bagi kehidupan masyarakat adat harusnya mendapat perlindungan dari pemerintah sebagai bagian dari hak hidup warga negara. Akan tetapi, kenyataannya banyak sekali kebijakan pemerintah saat ini yang bentrok dengan kepentingan masyarakat adat. Masyarakat adat banyak yang berhadapan untuk mempertahankan hak wilayah adatnya karena bersilang sengketa dengan Departemen Kehutanan atau bahkan pihak swasta yang turut memiliki kepentingan atas pengelolaan lahan tersebut. Konflik ini dapat terjadi karena adanya kesenjangan (gap) antara kebijakan dan kondisi faktual di lapangan (Pratiwi 2008).

Tulisan ini mengulas bagaimana masyarakat adat Cikondang memahami konsep, dan jenis lanskap yang ada serta dinamika lanskap yang terjadi sebagai hasil dari pola pengelolaannya. Gambaran pengetahuan dan penataan serta cara pengelolaan masyarakat adat dapat menjadi suatu pertimbangan bagi pemerintah setempat dalam membuat Peraturan Daerah kaitannya dengan perlindungan lahan adat khususnya Pemerintah Daerah Kabupaten Bandung.

\section{METODE}

Penelitian dilakukan pada bulan Mei tahun 2013 di Kampung Adat Cikondang, yang secara administratif termasuk dalam Desa Lamajang, Kecamatan Pangalengan, Kabupaten Bandung. Ketinggian tempat Kampung Adat Cikondang adalah sekitar $700 \mathrm{~m}$ dpl. Kampung Adat Cikondang berada di kaki Gunung Tilu. Secara georafis kampung Dukuh terletak pada 6 43' 0" S, 107 13' 33" E. Penduduk Kampung Adat Cikondang terdiri dari 290 Kepala Keluarga (KK) dengan 991 jumlah jiwa.

Metode penelitian yang dilakukan adalah eksplorasi yang didasarkan atas pendekatan emik dan etik. Pendekatan emik dilakukan untuk menggali dan mendapatkan data tentang pengetahuan masyarakat atas obyek yang sedang diamati dari sudut pandang dan bahasa mereka (Waluyo 2004). Selanjutnya melalui system of knowledge and cognition, pengetahuan masyarakat yang berupa kaidah konseptual, kategori, kode, dan aturan kognitif dibahas dan dianalisis berdasarkan kategori konseptual yang diperoleh dengan latar belakang ilmiah (etik). Pengetahuan masyarakat memanfaatkan tumbuhan dalam pengobatan di peroleh melalui wawancara kepada responden sebanyak 30\% dari total KK yaitu $87 \mathrm{KK}$ (Waluyo 2004), tokoh adat, dan informan kunci. Pengumpulan data pengetahuan masyarakat lokal digunakan teknik wawancara berencana (standardized interview), wawancara tidak berencana (unstandardized interview), dan wawancara sambil lalu (casual interview) kepada responden (Rugayah et al. 2004) menggunakan lembar wawancara Semistructured Interview dan Structured Interview. Data yang dikumpulkan terdiri atas pengetahuan masyarakat tentang satuan lanskap, ekologi setiap satuan lanskap, keanekaragaman tumbuhan pada setiap satuan lanskap, dan pemanfaatan tumbuhan dari setiap satuan lanskap. 


\section{HASIL DAN PEMBAHASAN}

Konsepsi Satuan Lanskap dan Unit Lanskap yang dikenali. Masyarakat Cikondang melakukan pengelolaan dan pemanfaatan terhadap sumber daya alam yang terdapat di sekitar wilayah kampungnya. Interaksi tersebut melahirkan satuan-satuan lanskap. Pola pengelolaan wilayah pada masyarakat adat didasarkan atas pengalaman atau sejarah yang terjadi. Berdasarkan fakta tersebut, dapat disintesis bahwa pengertian lanskap menurut masyarakat adat Cikondang adalah wilayah atau ruang terbuka yang memiliki fungsi tertentu untuk menyokong kehidupan sehari-hari, selain itu juga memiliki sejarah yang berkaitan erat dengan keberadaan masyarakat Cikondang.

Konsepsi masyarakat merumuskan karakter dalam menderminasi lanskap secara tidak langsung membuat nama lanskapnya. Nama Laskap yang dibuat oleh masyarkat Cikondang didasarkan atas karakter fungsi, ciri atau kepemilikan. Contoh nama lanskap yang didasarkan atas karakter fungsi adalah Lanskap Parabon berasal dari kata paranti ngebon (untuk berkebun) merupakan lanskap yang memiliki fungsi sebagai tempat untuk berkebun. Lanskap lamping merupakan contoh nama lanskap yang dibuat dari karakter cirinya. Lamping (lahan miring) merupakan lanskap yang memiliki ciri lahan dengan kemiringan lebih dari $45^{\circ}$, sehingga sulit untuk dijadikan lahan pertanian. Adanya bagian lanskap pesawahan yang merupakan titipan leluhur kepada adat, menjadikan masyarakat menamai lanskap pesawahan atas dasar kepemilikannya dengan sebutan Sawah Adat.

Berdasarkan hasil wawancara dan survey yang dilakukan terdapat 9 lanskap di Kampung Adat Cikondang (Gambar 1). Lebih lengkapnya penjelasan setiap lanskap fungsi, ciri, dan kepemilikan pada setiap lanskap diuraikan sebagai berikut.

Hutan Gunung Tilu. Hutan Gunung Tilu berupa hutan alami seluas 8.000 Ha yang pengelolaannya di bawah Departemen Kehutanan. Fungsi hutan ini sebagai Cagar Alam (CA) yang tidak boleh diekploitasi dan dikormersialisasi berdasarkan Keputusan Menteri Pertanian RI Nomor: 68/Kpts/ Um/2/78 ditetapkan tanggal 7 Februari 1978.

Hutan Gunung Tilu memiliki ciri hutan tipe hutan hujan tropis dengan kerapatan tumbuhan yang tinggi dan tutupan kanopi pohon yang rapat serta bagian dasar didominasi oleh keluarga jahejahean (Zingiberaceae) serta talas-talasan (Araceae). Sumber daya alam hutan gunung tilu masih sangat tinggi. Banyak tumbuhan yang berpotensi seperti kayu mala (Altingia excelsa), saninten (Casonopsis javanica), Pasang (Quercus sp), Teureup (Artocarpus

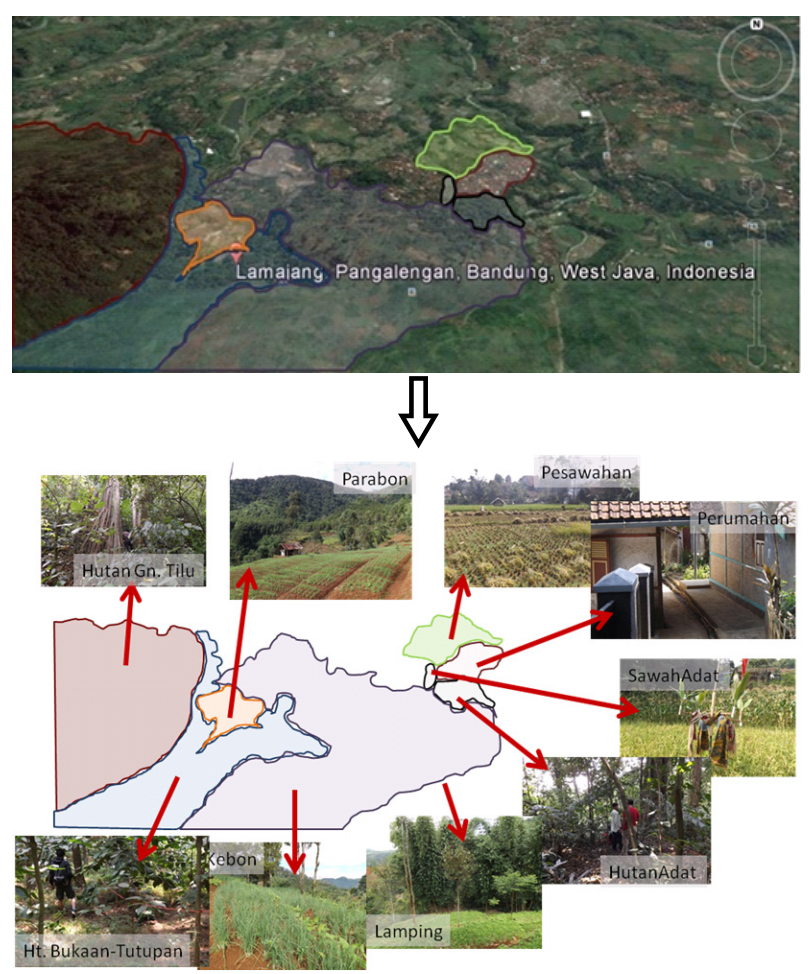

Gambar 1. Keanekaragaman lanskap kampung adat Cikondang.

elasticus), kondang (Ficus variegata), puspa (Schima wallichii), sarangan (Castanea argentea), dan handalaksa (Podocarpus neriifolius). Selain itu, keanekaragaman fauna yang ada seperti macan tutul (Panthera pardus), kera (Macaca fascicularis), Owa (Hylobates moloch), kijang (Muntiacus muntjak), lutung (Trachypitechus auratus), Surili (Presbytis comata), burung dederuk (Streptopelia bilorquata), dan ular sanca (Geopelia striata).

Hutan Bukaan-Tutupan. Hutan ini merupakan bagian dari Hutan Gunung Tilu seluas 25 Ha yang dikelola oleh Perhutani sebagai hutan produksi dan hutan penyangga (buffer zone). Dalam rangka peran serta masyarakat dan turut menjaga kelestarian CA Gunung Tilu, maka dibuat program hutan rakyat. Melalui program ini, perhutani bekerja sama dengan lembaga kelompok tani hutan yang dibentuk oleh masyarakat sekitar hutan. Kelompok tani hutan mengkoordinasikan anggotanya untuk mengolah lahan Hutan Bukaan-Tutupan agar bertani komoditas pertanian yang umurnya tahunan dan dapat panen setiap tahun. Beberapa komoditas pertanian yang diarahkan oleh perhutani adalah pinus (Pinus merkusii), dan kopi (Coffea sp.). Melalui program ini diharapkan petani tidak merusak hutan dan turut menjaga kelestarian CA Gunung Tilu.

Ciri lanskap ini berupa hutan homogen dengan tutupan kanopi yang renggang dari Pinus (Pinus merkusii), sedangkan bagian tengah cukup rapat ditutupi perdu dari Kopi (Coffea sp.) serta bagian dasar ditutupi oleh rumput-rumput yang sesekali 
dilakukan penjarangan rumput oleh petani. Pada beberapa bagian lanskap ini sudah mulai adanya beberapa benih komoditas baru yang ditanam seperti cengkeh (Eugenia aromatica) dan kapol (Amomum cardamomum).

Parabon. Parabon (paranti ngebon) artinya tempat berkebun, dimaksudkan sebagai lahan berkebun bagi kepala desa. Lahan ini merupakan lanskap transformasi dari hutan gunung tilu yang diserahkan kepada pemerintahan Desa Lamajang sebagai inventaris desa. Pemerintah desa tidak langsung menggarapnya, akan tetapi disewakan kepada masyarakat, dan hasil penyewaanya sebagai bagian kas pemasukan desa. Vegetasi Parabon berupa tanaman herba kecil musiman yang ditanam serempak seperti Kentang (Solanum tuberosum), Tomat (Solanum lycopersicum), Bawang Merah (Allium cepa), dan beberapa komoditas sayuran musiman lainnya.

Kebon. Kebon merupakan lanskap yang dimiliki masyarakat, digunakan sebagai tempat berkebun, menanam sayuran, buah-buahan, dan palawija. Vegetasi untuk kebun ada dua tipe. Pertama, kebun sayuran memiliki vegetasi tanaman herba kecil musiman seperti halnya di Parabon. Kedua, Kebon dengan vegetasi semak, perdu dan pohon yang umurnya tahunan yang termasuk kedalam kelompok palawija, buah-buahan, dan jenis kayu. Kebon jenis kedua ini lebih sedikit dibanding jenis pertama. Masyarakat lebih dominan bertani sayuran, karena akan memperoleh hasil panen lebih cepat dibandingkan jika menanam palawija, buah, dan kayu. Selain itu, kampung Cikondang dikenal sebagai salah satu wilayah penghasil sayuran sehingga menjual sayuran lebih mudah dibanding palawija, buah dan kayu. Aktivitas pertanian di lanskap ini sama dengan parabon yaitu dengan sistem semi organik.

Lamping. Lanskap ini merupakan lahan miring yang curam dengan sudut kemiringan lebih dari $45^{\circ}$. Lamping dikelola masyarakat sesuai aturan adat ditanami bambu, sehingga vegetasi yang terbentuk berupa semak-semak diselingi rumput dengan beberapa rumpun bambu. Tepian sungai yang bertopografi miring hingga curam juga merupakan tempat penanaman bambu (Arinasa 2005).

Beberapa spesies bambu yang ditanam pada Lanskap inidiantaranyahaur (Bambusa tuldoides), Awi koneng (Bambusa vulgaris), Awi tali (Gigantochloa apus), Awi temen (Gigantochloa atter), dan Awi gombong (Gigantochloa pseudoarundinacea). Melimpahnya bambu di Kampung ini berimbas pada kegiatan industri kreatif masyarakat yang terbiasa membuat berbagai kerajinan dan peralatan rumah tangga yang berbahan dasar bambu. Beberapa produk kreatif yang dibuat seperti adalah boboko (tempat nasi), nyiru, gelas bambu, sendok bambu, alat musik, gantungan kunci. Aktivitas kerajinan ini cukup membantu perekonomian masyarakat selama menunggu musim panen datang, akan tetapi aktivitas ini belum dikelola dengan baik sehingga belum menjadi komoditas unggul di desa ini.

Hutan Awisan. Hutan Awisan merupakan hutan adat yang di dalamnya terdapat bumi adat, leuit (lumbung padi), lisung (alat penumbuk padi), pancuran (sumber air jamban), tampian (jamban), dan balong (kolam) yang sifatnya ' $n u$ pondok tong disambung nu panjang tong dipotong' (tidak boleh dirubah, ditambah, dan dihilangkan) serta di bagian paling atas dataran hutan awisan ini terdapat makam adat. Luas hutan Awisan sekitar $3 \mathrm{Ha}$ termasuk dengan Sawah adat. Karena dijadikan cagar dan warisan budaya masyarakat Cikondang yang ditetapkan melalui Undang-undang No 5 Tahun 1992, maka tidak ada yang berani merubah bentuk dan tatanan di dalamnya, sehingga kebun belakang rumahnya menjadi belantara seakan-akan seperti hutan. Dari sinilah masyarakat menyebutnya sebagai Hutan Awisan yang bermakna sebagai hutan yang harus dijaga.

Hutan awisan memiliki vegetasi seperti hutan dengan tutupan kanopi yang rapat sedangkan di bagian dasar hanya terdapat beberapa semai dan tiang dari spesies pohon-pohon yang besar. Beberapa pohon yang terdapat di Hutan awisan adalah Teureup (Artocarpus elastic), Durian (Durio zibethinus), Jambe (Areca catechu), Jangkurang (Schefflera scanden), dan Kawung (Arenga pinnata). Hutan awisan ini milik adat, dan sumber daya di dalamnya digunakan untuk kegiatan upacara adat. Pengelolaan dan penggunaan sumber daya di Hutan Awisan ini dilakukan atas kebijakan musyawarah adat yang dipimpin ketua adat dan sesepuh adat.

Sawah Adat. Lanskap ini merupakan bagian dari lahan adat yang terdapat di samping Hutan Awisan bagian lembah. Pengelolaannya ditujukan untuk kesejahteraan pelaksanaan upacara adat. Vegetasi yang terbentuk berupa hamparan pesawahan yang terdiri dari beberapa kultivar padi lokal seperti Pare Agogo, pare beureum jaka, Pare Cere Hideung (lokal), Pare Cere Koneng (lokal), pare gadog, pare gemar, Pare Hawara Geulis (lokal), Pare Hawara Kalapa (lokal), Pare Hawara Kapas Beureum (lokal), Pare Hawara Kapas Bodas (lokal), Pare Ketan Beureum (lokal), Pare Ketan Bodas (lokal), Pare Ketan Hideung (lokal), Pare morneng, Pare Racik (lokal), Pare Ranggeuyan, Pare Rebon (lokal), pare sinta pendek, Pare Sri Dewi. 
Perkampungan. Wasiat Uyut Pameget sebagai leluhur Cikodang telah menetapkan bahwa untuk membuat rumah senantiasa pada lahan yang datar, sedangkan lahan yang cekung menampung air digunakan untuk membuat kolam. Perumahan dan kolam berada pada satu wilayah lanskap Perkampungan. Perkampungan tersusun atas 991 orang penduduk yang tersebar pada $290 \mathrm{KK}, 2 \mathrm{RW}$ dan 8 RT. Pemukiman penduduk cukup rapat dan terkumpul pada satu wilayah perkampungan. Hampir setiap rumah memiliki pekarangan dan beberapa memiliki kolam.

Pesawahan. Lahan sebelah bawah kampung dibuatkan sengkedan membentuk terasering untuk lahan pesawahan. Terasering pada sawah mengikuti garis kontur dan petak yang hampir datar serta pematang berfungsi untuk menahan air (Soemarwoto 1983). Sumber daya yang ada pada lanskap ini didominasi oleh pare (Oryza sativa). Pada beberapa petak sawah ada yang memanfaatkan untuk ditanam palawija secara tumpang sari seperti Jagong (Zea mays), Cabe (Solanum annum), dan Kalapa (Cocos nucifera) pada pematang sawahnya.

Dinamika Transformasi Lanskap. Dinamika kehidupan masyarakat dengan lingkungan merupakan cerminan transformasi lanskap yang menjadi jati diri Kampung Adat Cikondang sampai saat ini. Proses dan dinamika transformasi terjadi karena adanya faktor internal dan eksternal. Faktor internal didefinisikan sebagai kebutuhan masyarakat terhadap sumber daya alam, yang berhubungan dengan kebutuhan dasar manusia untuk hidup. Faktor eksternal di antaranya adalah kebijakan luar yang mengikat masyarakat cikondang (pemerintah, dan penjajah belanda) dan ideologi yang dapat masuk dalam bentuk budaya, intelektual, dan politik.

Masyarakat adat cikondang masuk pertama kali ke dalam wilayah kaki gunung tilu (yang sekarang menjadi kampung cikondang) konsep lanskap yang terbentuk sangatlah sederhana. Lanskap yang terbentuk dipengaruhi faktor internal saja, sehingga hanya ada lanskap perkampungan, gunung tilu, dan kebon. Namun seiring waktu faktor luar akan mempengaruhi pemikiran masyarakat atau bahkan memaksa untuk menata ulang lanskap yang ada agar kepentingan masyarakat tetap terakomodir.

Gambaran hubungan antar lanskap menunjukkan bahwa setiap lanskap memiliki peranan dalam kehidupan masyarakat adat (Gambar 2). Setiap satuan lanskap lahir dari satuan lanskap yang ada sebelumnya. Awal mula masyarakat masuk ke wilayah sekarang hanya mengenal tiga lanskap, yaitu hutan gunung tilu, perkampungan, dan kebon. Selanjutnya setelah masuknya padi sebagai komoditas pertanian, masyarakat adat berpindah dari petani kebon menjadi petani sawah sehingga lanskap kebon berubah menjadi sawah, dan masyarakat membuka kembali lahan kebon dari bagian lanskap hutan gunung tilu. Dalam proses pembukaan lahan gunung tilu menjadi kebon, ditemukan lanskap yang cukup curam dan sulit ditanami yang disebut lamping. Kejadian Bandung Lautan Api menyebabkan terjadinya pembumi hangusan perkampungan, dan tersisa rumah leluhur saja yang tidak terbakar. Hal ini memperkuat keyakinan warga kepada leluhurnya, sehingga menjadikan rumah leluhur dikeramatkan dijadikan lanskap hutan awisan. Begitupun sawah leluhur dijadikan sawah adat. Pada transformasi selanjutnya hasil dari kebijakan pemerintah memunculkan lanskap parabon yang dijadikan inventaris desa dan lanskap hutan bukaan-tutupan yang difungsikan sebagai hutan penyangga.

\section{PEMBAHASAN}

Lanskap terbentuk sebagai akibat dari pola intervensi masyarakat dalam mengekplorasi sumber daya alam dari wilayah tersebut (Rahayu et al. 2005). Satuan lanskap di kampung adat Cikondang mampu dideterminasi oleh masyarakat secara baik. Indikator untuk membedakan satuan lanskap dibedakan atas fungsi, ciri dan kepemilikannya. Begitupun pada masyarakat Wawonii di Pulau Wawonii Provinsi Sulawesi Tenggara, mampu membedakan satuan lanskapnya atas dasar fungsi dan penampakannya (Rahayu et al. 2005). Dasar determinasi fungsi dan ciri lanskap ini memang yang paling banyak dilakukan dan umum. Karakter fungsi pada lanskap selalu mengingatkan masyarakat akan manfaatnya, sehingga masyarakat akan senantiasa mengingatnya selama manfaat lanskap tersebut dibutuhkan. Selain itu, karakter ciri lanskap juga menjadi dasar untuk membedakan lanskap sehingga mudah menemukan dan menunjukan batas dari lanskap tersebut. Pada masyarakat Cikondang ditemukan juga karakter kempemilikan untuk membedakan satuan lanskap yang ada. Karakter kepemilikan muncul karena masyarakat mengenal lanskap tersebut dimiliki oleh tokoh yang dihargai atau disegani oleh masyarakat.

Kawasan CA Gunung Tilu merupakan salah satu sisa hutan alam di Jawa Barat yang relatif masih cukup lestari. Hal ini karena masyarakat sekitar gunung yang sangat bijak menempatkan gunung tilu tidak sebagai objek eksploitasi, termasuk masyarakat adat Cikondang. Banyak kelompok tani hutan yang bermitra dengan dinas kehutanan dalam menjaga keasrian hutan gunung tilu. Mitra Pasundan merupakan salah satu kelompok tani hutan 


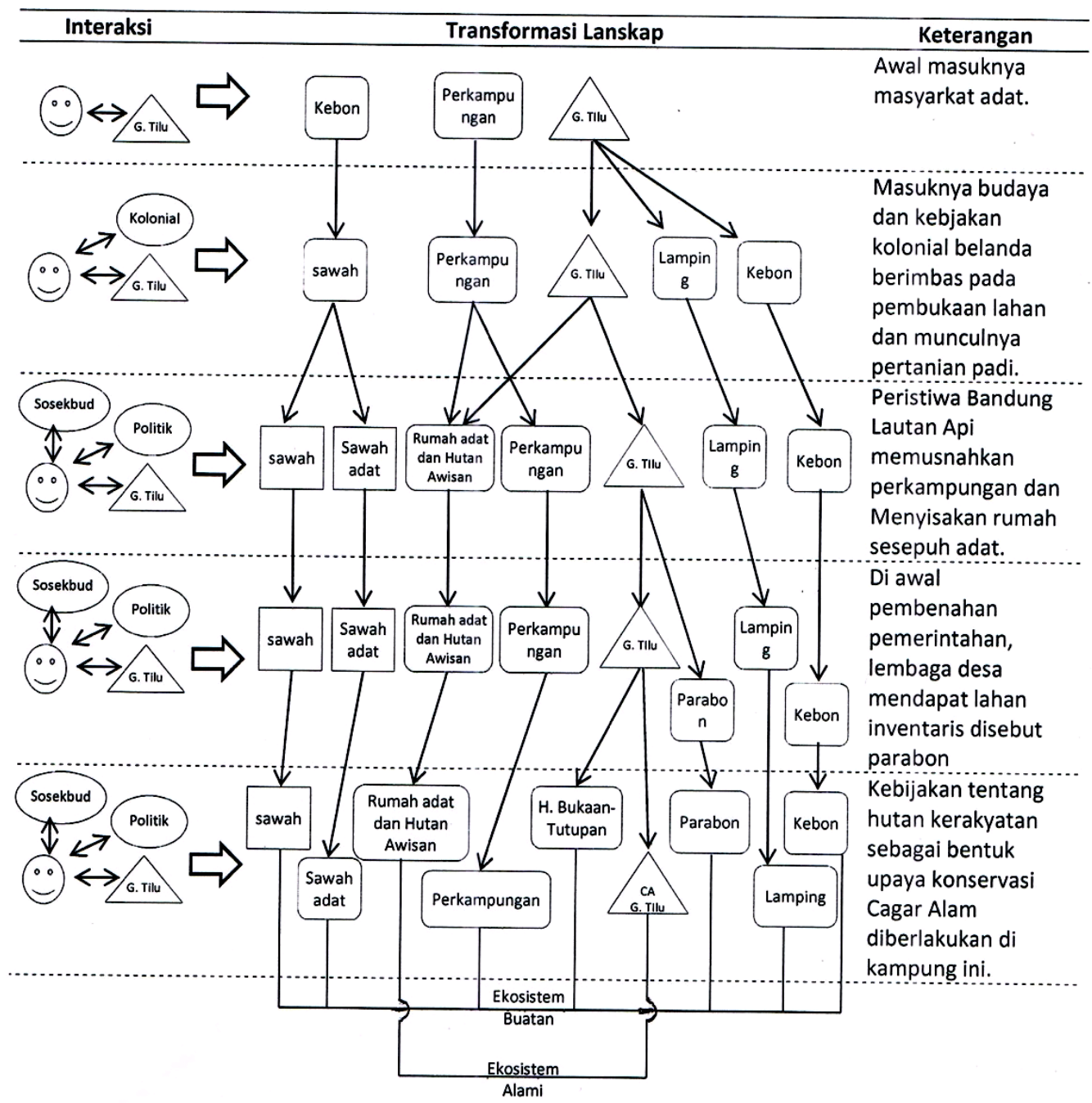

Gambar 2. Proses terbentuknya satuan lanskap serta transformasinya.

yang senantiasa melakukan penanaman sekaligus menyediakan bibit untuk penghijauan di Hutan Gunung Tilu sebagai kewajiban dari hak mendapat lahan kelola hutan produksi. Namun dilain pihak, masih ada pula beberapa permasalahan perusakan dan pembalakan hutan di beberapa titik seperti kasus di Desa Gambung (Kawasan Cagar Alam Gunung Tilu Terancam Rusak, Pikiran Rakyat, 04/11/12). Besarnya potensi sumber daya alam hutan gunung tilu dan mulai munculnya beberapa permasalahan serta peranannya sebagai daerah resapan untuk sumber air citarum medesak untuk adanya penangan yang bersifat komprehensif. Salah satu bentuk penangannnya adalah dengan Program Desa Konservasi, program ini merupakan kerjasama Kementrian Kehutanan, BKSDA Jabar, dan Asean Development Bank (ADB). Program ini mengagas desa-desa di kawasan penyangga hutan gunung tilu dijadikan sebagai desa konservasi.

Kegiatan masyarakat pada lanskap Hutan Gunung Tilu hanya terbatas memanfaatkan tumbuhan obat di sekitar CA Gunung Tilu (Oktaviana 2008), mengambil kayu bakar dari ranting yang patah, mengambil beberapa tumbuhan untuk ritual seperti daun pisang kole (Musa acuminata), dan sisanya kegiatan konservasi untuk senantiasa menjaga kelestarian gunung tilu agar ketersediaan air ke kampung dapat terjaga. Beberapa kegiatan konservasi yang dilakukan, antara lain menanam pohon, karena ada aturan adat yang mengharuskan menanam 10 pohon apabila mendapatkan adanya pohon yang tumbang. Selain itu, dalam ritual adat ada juga kegiatan hajat cai dan solokan (Syukuran air dan saluran air), kegiatan ini dilakukan dengan melakukan pembersihan saluran air dan diakhiri dengan syukuran di mata air yang dilakukan setiap tahun.

Pengelolaan Hutan Bukaan-Tutupan merupakan bagian dari pemberdayaan masyarakat Cikondang dalam kegiatan hutan kerakyatan. Selain sebagai bagian dari tuntutan adat untuk menjaga Gunung Tilu, ada manfaat secara materil dengan mengolah lahan Hutan Bukaan-tutupan. Pada beberapa kampung adat, dikenal juga sistem hutan produksi ini. Kelompok 
adat Ciptagelar mengenal Hutan Bukaan-Tutupan sebagai hutan bukaan. Marina dan Dharmawan (2011) menjelaskan bahwa masyarakat Ciptagelar mengenal tiga jenis hutan yang dikategorikan oleh adat, yaitu Leuweung tutupan (hutan tutupan), Leuweung titipan (hutan titipan), dan Leuweung bukaan (hutan bukaan). Pemeliharaan hutan melalui penyediaan hutan bukaan-tutupan memberikan pengaruh positif, antara lain 1) Menjaga stabilitas dan perlindungan tanah dari erosi, 2) mencegah banjir dan menyediakan tanah subur, 3) Mengatur suhu udara pada daerah sekitarnya, 4) Pemeliharaan serta tempat hidup dan berkembang biaknya jenis hewan yang dilindungi maupun yang tidak dilindungi, 5) Menghindari pendangkalan sungai, danau, waduk dan lain-lain (Berthe and Freidberg 1995). Pelaksananaan program ini di kampung adat tidak sepenuhnya berjalan dengan lancar, ada beberapa permasalahan yang muncul seperti petani menjual hak pengolahan lahan kepada perusahaan. Hal ini menyebabkan pertani akhirnya hanya sebagai buruh tani saja dan yang mendapatkan keuntungan adalah perusahaan tersebut.

Aktivitas masyarakat dalam mengolah lahan parabon tidak jauh berbeda dengan mengolah kebon, yang membedakan adalah kepemilikannya saja. Pertanian sayur masyarakat cikondang masih semi konvensional, tidak banyak teknologi yang dipakai. Penggunaan bahan kimia sudah mulai berkurang, dibarengi dengan penggunaan pupuk kandang. Setiap awal tanam, setiap masyarakat adat senantiasa melakuan ritual di rumah masing-masing dengan harapan agar musim tanam yang akan dilakukan menghasilkan panen yang melimpah.

Secara garis besar manajemen pengelolaan lahan berdasarkan perspektif masyarakat Kampung Adat Cikondang Cikondang dikelompokkan menjadi empat tipe lahan, hal ini untuk menunjukkan adanya beberapa kesamaan dari sembilan lanskap yang ada (Gambar 3.). Kesamaan tipe lahan terlihat dari vegetasinya seperti pada tipe lahan hutan yang terdiri dari hutan gunung tilu, dan hutan bukaan-tutupan. Adapula yang memiliki kesamaan dalam fungsi sebagai sumber kehidupan yaitu tipe lahan garapan yang terdiri dari lanskap parabon, lamping, kebon, dan sawah. Tipe lahan adat lebih pada kepemilikannya, yaitu milik adat yang pengelolaannya terikat pada adat seperti lanskap hutan awisan dan sawah adat. Tipe lahan kampung hanya terdiri dari lanskap perkampungan karena untuk tempat tinggal pada masyarakat Cikondang berkumpul pada satu titik di bukit yang sekarang disebut sebagai kampung cikondang. Setiap tipe lahan dan satuan lanskap terbentuk dari dinamika masyarakat. Seiring dengan waktu, dinamika masyarakat akan mungkin terus mengembangkan munculnya lanskap baru atau mungkin pula akan merubah tatanan lanskap yang ada.

Setiap satuan lanskap memberikontribusi yang penting bagi kehidupan masyarakat karena terdapat pola hubungan dinamika masyarakat dan satuan lanskap. Dinamika perubahan penduduk, seperti pertambahan penduduk, kegiatan ekonomi dan sosial budaya, aturan baru dari pemerintah dan kemajuan teknologi melahirkan satuan-satuan lanskap yang berbeda antar tempatnya (Rahayu et.al 2005; Waluyo 2000).

Pola transformasi dan lahirnya lanskap di Kampung Adat Cikondang menunjukkan adanya transformasi lanskap gunung tilu yang senantiasa dibuka oleh masyarakat. Ketinggian lanskap pesawahan sampai ke gunung tilu menunjukkan adanya runtutan posisi dari dataran rendah ke bukitbukit kecil, ke kaki gunung dan akhirnya masuk ke bagian gunung (Gambar 4).

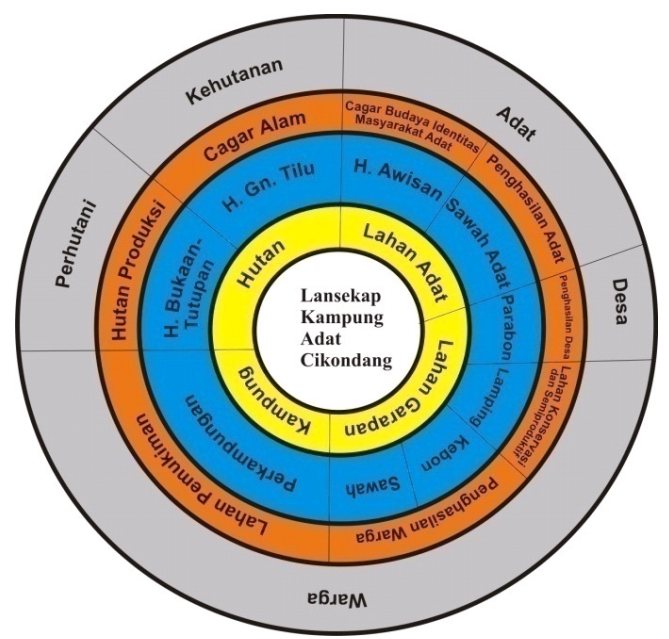

Gambar 3. Manajemen pengelolaan lahan berdasarkan perspektif masyarakat kampung adat cikondang. $\square$ tipe lahan, $\square$ satuan lanskap, $\square$ fungsi lahan, $\square$ kepemilikan.

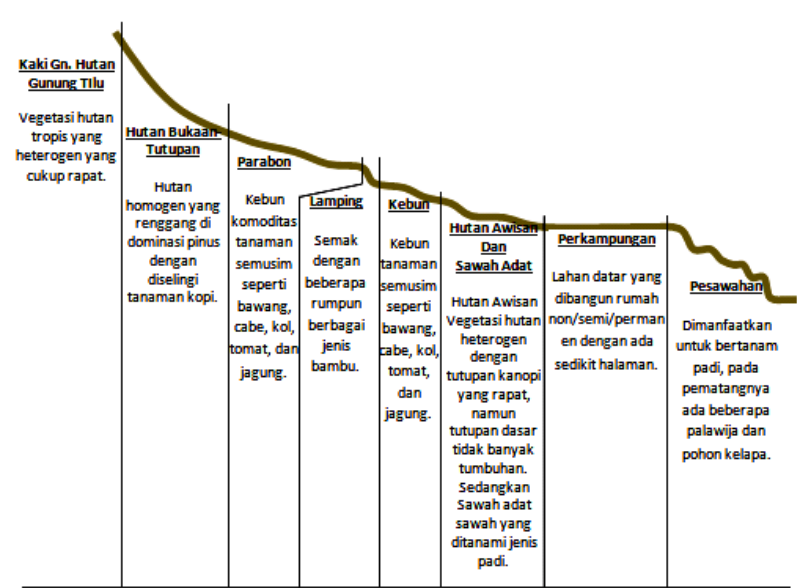

Gambar 4. Topografi satuan lanskap dan karakteristik lahan Kampung Adat Cikondang. 
Posisi Hutan Bukaan-Tutupan dan Parabon merupakan lanskap yang paling dekat dengan lanskap Hutan Gunung Tilu (Gambar 4). Hutan Gunung Tilu menjadi lahan produktif (parabon dan hutan bukaan-tutupan) memperlihatkan bahwa hutan bukaan-tutupan, dan parabon berada pada topografi yang miring sebagai bagian wilayah kaki gunung tilu. Sedangkan lanskap lainnya berada pada topografi yang sesuai dengan aturan adat, seperti lamping berada pada topografi yang curam, kebun berada pada topografi yang terjal, hutan awisan tepat berdekatan dengan perkampungan yang datar, dan pesawahan dengan topografi yang terjal di bawah perkampungan.

\section{UCAPAN TERIMA KASIH}

Ucapan terimakasih penulis sampaikan kepada masyarakat kampung adat Cikondang Des Lamajang Kabupaten Bandung yang telah memberikan dukungan dan kerjasamanya selama pengambilan data di lapangan. Secara khusus, ucapan terimakasih disampaikan kepada Bapak Ilin Darsyah, Bapak Engkan Karsono dan Bapak Ano yang telah banyak membantu dalam memberikan informasi dan mendampingi selama penelitian.

\section{DAFTAR PUSTAKA}

[BKDJB] Bidang Kebudayaan Disbudpar Jawa Barat. 2009. Data Kampung Adat di Jawa Barat, Bandung. http://www.disparbud.jabarprov.go.id/wisata/fupload/Data\%20Kampung\%20 Adat\%20di\%20Jawa\%20Barat.pdf [13 Februari 2013].

Arinasa IBK. 2005. Keanekaragaman Dan Penggunaan Jenis-Jenis Bambu DiDesa Tigawasa, Bali.Biodiversitas.6(1): 17-21.
Dasyah I. 2004. Mutiara Ilmu Masyarakat Hukum Adat Kampung Cikondang. Dokumen Pribadi Tidak Diterbitkan.

Dasyah I. 2006.Situs Cagar Budaya Rumah Adat KiSunda Kampung Cikondang.Dokumen Pribadi Tidak Diterbitkan.

Marina I, Dharmawan AH. 2011. Analisis Konflik Sumberdaya Hutan di Kawasan Konservasi. Jurnal transdisiplin sosiologi, komunikasi, dan ekologi manusia. 5(1): 90-96.

Oktaviana LM. 2008. Pemanfaatan Tradisional Tumbuhan ObatOleh Masyarakat Di Sekitar KawasanCagar Alam Gunung Tilu, Jawa Barat [Skripsi]. Bogor: Fakultas Kehutanan, Institut Pertanian Bogor.

Pratiwi S. 2008. Model pengembangan institusi ekowisata untuk menyelesaikan konflik di Taman Nasional Gunung Halimun Salak [disertasi]. Bogor: Sekolah Pascasarjana, Institut Pertanian Bogor.

Rahayu M, Rugayah dan Sukardi. 2005. Etnobotani Masyarakat Wawonii Pulau Wawonii Sualwesi Tenggara. Laporan Teknik 2005 Bidang Botani, Puslit Biologi LIPI.

Sastrapradja et al. 1979. Tanaman Pekarangan. Bogor (ID): Lembaga Biologi Nasional-LIPI.

Waluyo EB, Soedjito H, Widjaja EA, Rifai MA. 1991. Penguasaan Etnoekologi Secuplikan Masyarakat Etnik di Indonesia. Makalah Utama pada KIPNAS V. LIPI Jakarta 3-7 September 1991.

Waluyo EB. 2000. Memanfaatkan Isu Etnik Melalui Penelitian Etnobotani Untuk Pelestarian Plasmanutfah: Pengetahuan Sispa Dan Sumber Daya Siapa. Makalah pada Simposium Nasional Pengelolaan Plasma Nutfah dan Pemuliaan. Bogor 22-23 Agustus 2000.

Waluyo EB. 2004. Pengupulan Data Etnobotani. Di dalam: Rugayah, Widjaja EA, Praptiwi, editor. Pedoman Pengumpulan Data Keanekaragaman Flora. Bogor (ID): Pusat Penelitian Biologi-LIPI.

Waluyo EB. 2008. Review: Research Ethnobotany in Indonesia and the Future Perspective. Biodiversitas 9:59-63.

Waluyo EB. 2009. Etnobotani: Memfasilitasi Penghayatan, Pemutakhiran Pengetahuan dan Kearifan Lokal dengan Menggunakan Prinsip-prinsip Dasar Ilmu Pengetahuan. Prosiding Seminar Nasional Etnobotani.Puslit Biologi Cibinong 12-20 Mei 2009. 